The management of Australia's national parks could be selectively privatised. The government could put the implementation of the plan of management out to tender and monitor the performance of the successful bidder. Competition between bidders would ensure that the goals of the plan of management would be realised in the most cost-effective manner.

Clubs and associations could be encouraged to purchase areas for nature protection purposes. Governments could direct funds allocated to conservation organisations away from untied grants and towards the subsidisation of land purchases. They could invite selected associations to put forward proposals for areas of land to be protected, vet the proposals, and allocate funds to supplement money raised by the associations for the purchases. Ownership of the areas so purchased would be vested in the associations but specific covenants could be included on the titles to limit land use to nature protection. This mechanism would inject some market discipline into the process of adding to the stock of nature protection areas.

A system of nature protection that takes advantage of the strengths of both the private and the public sectors would ensure that the limited resources available for nature protection are used to best advantage.

Jeff Bennett is Associate Professor of Economics at the University of New South Wales.

\title{
Are Tobacco Taxes Too High?
}

\section{Robert Albon}

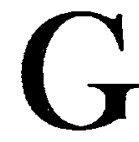

overnments have intervened in various ways in the production, sale and consumption of tobacco products. Perhaps some of these interventions are in the public interest as usually interpreted, but some may reflect political correctness, pressure from special interests and a preoccupation with costs. Recently some rather draconian proposals have emerged, including blanket bans in pubs, restaurants and clubs, and even the suggestion that smoking, which is already subject to the highest tax rate of any commodity (about 190 per cent), be taxed at an infinite rate (that is, banned).

A balanced debate on smoking would exhibit the following three characteristics:

- Recognition that there are benefits to smokers, measured by what smokers are prepared to pay to smoke. To assume otherwise is inconsistent with the principles of a free society. Many observations on smoking are based solely on 
costs, apparently stemming from the influential study of the costs of drug use by Collins and Lapsley (1989).

- Application of the conventional efficiency criterion, based on the summation of all benefits and costs in dollar terms, irrespective of the identity of the individuals to whom the benefits or costs are attached. If this is a positive sum, the industry is desirable and any policy change which increases this sum increases its desirability.

- Application of notions of fairness, including avoidance of regressivity and discrimination.

The main public policy issues emerge easily, revolving especially around the implications of divergences of social and private costs: the costs to non-smokers from the smoke created by others; the costs to the community of treating smoking-related diseases; and whether there is a rationale for the extraordinarily high levels of taxation imposed by the Commonwealth and the States.

\section{Second-Hand Smoke: Smells and Health Risks}

The unpleasantness and health risks associated with second-hand smoke and smells have given rise to various legislative endeavours (usually in the form of bans on smoking in many work-places, airports, aircraft, and so on) and social adjustments of various kinds.

Three points may be made about these changes. First, the costs have always fallen on smokers. Whether this is fair or not is a matter of individual judgment, but the direction of the cost burden is clear.

Second, from an efficiency viewpoint, it is not clear that the use of bans is warranted in all circumstances. The approach developed by Ronald Coase (the Coase Theorem) might yield an efficient solution with a positive amount of smoking in some circumstances. If property rights were allocated either to non-smokers (the right to clean air) or to smokers (the right to smoke), these rights would be tradable. For example, if non-smokers had the right to clean air, smokers could smoke only in a particular place if they compensated non-smokers by an amount determined by them. The smokers may be prepared to pay more, up to some level of smoking, than non-smokers need in compensation. In other circumstances the cost of even one unit of smoking could exceed the benefit, and zero smoking would be efficient. It may be possible for an efficient solution to arise even where property rights have not been allocated. The essence of Coase's approach is that the 'right' amount of smoking arises in a market context, but only where transaction costs between the parties are sufficiently low. There are probably circumstances (for example, lifts) where bargaining costs are too high, and a ban may be appropriate.

Third, in spite of the efforts of a number of special interests, the political process has so far been unwilling or unable to extend complete bans to bars, clubs and 
restaurants in any jurisdiction. Perhaps this reflects a realisation that bans in specific areas have gone far enough, and that it is time for voluntary actions to take over.

\section{Health Costs}

Now consider the second possible divergence of social and private costs. The Collins and Lapsley study concentrated on the costs of smoking and other drug usage and gave the impression that smokers do not pay their way with respect to health costs. However, as has been convincingly shown in a study by ACIL (1994), Collins and Lapsley overestimate the costs that can be attributable to smoking, do not differentiate between social and private costs, and in other ways misrepresent the true situation.

According to ACIL, the health costs of smokers imposed on the community through the socialised health system in $1992 / 93$ were less than $\mathbf{A} \$ 400 \mathrm{~m}$. These are health costs of smokers that are not borne by the smokers themselves. This may seem to be a large amount in absolute terms, but not when compared with the revenue received by Commonwealth and State governments from tobacco taxes: $\$ 2,963 \mathrm{~m}$ in $1992 / 93$. That is, smokers are taxed more than $\$ 2,500 \mathrm{~m}$ in excess of the level necessary to meet their public-health costs.

\section{The Right Tax Rate}

Governments have to get their net revenue from somewhere, and tobacco products are, along with other commodity taxes, income taxation, and so on, a source of that net revenue. But we can apply equity and efficiency criteria when enquiring whether governments try to get too much net revenue from tobacco products.

Is the high rate of tax fair? First, the tobacco tax rate stands out as being by far the highest for any commodity group. The combined Commonwealth and State tax rate for tobacco products is over 190 per cent (a carton of 200 Marlboro cigarettes costs $\$ 12$ in the Canberra downtown duty-free store and around $\$ 35$ in Canberra supermarkets). The next highest - on spirits - is only about 120 per cent. If the contribution to health costs is removed, the rate of taxation on tobacco products is still higher than the rate on any other of the range of highly-taxed products, even without taking out their excess health costs.

Second, although some might regard it as fair to charge excess health costs to smokers, the idea would be more appealing if allgroups (drinkers, drug users, hanggliders, gluttons, and so on) paid their excess health costs through a special tax or user charges. Clearly this is not the situation at present.

Third, tobacco taxes are highly regressive. This arises from the combination of inelastic demand (own-price elasticity-of-demand estimates range from -0.2 to -0.57 : ACIL, 1994:24-5) and a concentration of smokers in low income groups (ACIL, 1994:47). Low-income smoking households sacrifice products other than tobacco when prices are raised by taxation. The high-tax regime on tobacco could be removing the sausage-meat from many a poor child's dinner table. 
Are the high taxes efficient? As with virtually any tax, there is an excess burden or deadweight loss from taxing tobacco products. As a tax rate applied to a particular base is increased, the total deadweight loss from the tax increases. Further, the deadweight loss increases at an increasing rate.

To achieve efficiency in raising a given total revenue from a variety of taxes, it is necessary to equalise the marginal excess burden from each. Where marginal excess burdens differ, an efficiency gain would result from reducing those with relatively high marginal excess burdens, and increasing those with relatively low ones.

On the basis of this efficiency criterion, there is prima facie evidence that tax rates on tobacco products, as the highest on any commodity group, are too high. To determine whether this rate could be in excess of the efficient level it would be necessary formally to examine the relationship between marginal excess burdens and tax rates for major taxes, but this would represent a large econometric task.

The rate may be in danger of becoming too high in a sense more relevant to governments: revenue. Taxation revenue rises at a decreasing rate as the tax rate is increased, eventually peaking and then falling. This relationship - the 'Laffer curve' - could indicate that governments are close to going too far with tobacco taxes and that an increase in rates could decrease revenue.

\section{Conclusion}

In recent years the debate on smoking has moved outside the usual bounds of public policy discourse. Political correctness has become an important factor; consumer sovereignty, faimess and economic efficiency have been down-played or ignored. Robert Tollison and Richard Wagner (1988) have warned of the slippery slope: a slide into other incursions on individual freedoms.

\section{References}

ACIL Economics \& Policy Pty Ltd (ACIL) (1994), Smoking: Cosis and Benefits for Australia, Canberra.

Collins, D. \& H. Lapsley (1991), Estimating the Economic Costs of Drug Abuse in Australia, National Campaign Against Drug Abuse, AGPS, Canberra (Monograph series No. 15).

Tollison, R. \& R. Wagner (1988), Smoking and the State, D. C. Heath, Lexington, Mass.

Robert Albon is Senior Lecturer in Economics in the Faculty of Economics and Commerce at the Australian National University. 